\title{
ANALISIS PADA PEKERJAAN GALIAN UNTUK MENCARI PRODUKTIVITAS DAN KOMBINASI ALAT BERAT DI PROYEK PEMBANGUNAN REFINERY DI PT. SALIM IVOMAS PRATAMA, TBK.
}

\author{
Mauliddiyah Ainurrizki', Siti Choiriyah², Theresia MCA ${ }^{3}$ \\ ${ }^{1}$ Jurusan Teknik Sipil, Fakultas Teknik Sipil dan Perencanaan, Institut Teknologi Adhi Tama Surabaya \\ 2,3 Jurusan Teknik Sipil, Fakultas Teknik Sipil dan Perencanaan, Institut Teknologi Adhi Tama Surabaya \\ Email : $\underline{\text { siti.choiriyah@itats.ac.id }}$
}

\begin{abstract}
ABSTRAK Pekerjaan tanah dalam suatu proyek pembangunan gedung merupakan salah satu bagian yang sangat penting. Pekerjaan tanah disini adalah pekerjaan galian dan pengangkutan. Untuk mempermudah dan mempercepat pekerjaan tanah diperlukan bantuan alat yaitu alat berat. Pada proyek pembangunan refinery di Perak barat, Surabaya memiliki akses jalan yang sempit, sehingga mobilisasi alat berat terbatas. Maksud dari penelitian ini adalah menghitung jumlah produktivitas alat berat dalam pekerjaan pembangunan pabrik dan tujuan dari penelitian ini adalah untuk mengetahui kombinasi alat berat yang optimal. Untuk mengetahui produktivitas alat berat khususnya excavator dan dump truck dilakukan dengan metode perhitungan berdasarkan data analisa di lapangan. Hasil dari perhitungan maka diperoleh produktivitas/kombinasi alat berat. Hasil perhitungan alat berat pada pekerjaan galian di proyek pembangunan refinery PT. Salim Ivomas Pratama, Tbk Kombinasi yang efisien yaitu Kombinasi keempat terdiri dari 1 unit Shovel, 1 unit excavator dengan unit excavator dengan jenis/tipe Long Arm 320 dengan kapasitas bucket $0,90 \mathrm{~m}^{3}$ dan 10 unit dump truck jenis/tipe Hino dutro $130 \mathrm{HD}$ dengan kapasitas $10 \mathrm{~m}^{3}$. Total produktivitas untuk shovel didapat dari 32 $\mathrm{m}^{3}$ produktivitas/jam x 8 jam kerja/hari $=256 \mathrm{~m}^{3} /$ hari, Total produktivitas untuk excavator didapat dari $32,8 \mathrm{~m}^{3}$ produktivitas/jam x 8 jam kerja/hari $=262,4 \mathrm{~m}^{3} /$ hari dan total produktivitas dump truck didapat dari $5,16 \mathrm{~m}^{3}$ produktivitas/jam x 8 jam kerja/hari $=41,3$ m³/hari. Kombinasi keempat menghasilkan waktu 25 hari.
\end{abstract}

Kata kunci : galian tanah, produktivitas, excavator, dumptruck, kombinasi

\section{PENDAHULUAN}

Pada proyek-proyek konstruksi saat ini, pengunaan alat berat merupakan hal terpenting. Karena dalam setiap pembangunan proyek menggunakan alat berat dengan berbagai fungsi, jenis, bentuk dan merk. Dalam pembangunan proyek-proyek kostruksi tersebut penggunaan alat berat berperan penting sebagai pengaruh dalam finansial dan kelangsungan pekerjaan di proyek.

Pematangan atau persiapan lahan akan terjadi pada setiap proyek konstruksi. Pada proses penyelesaiannya dibutuhkan bantuan alat berat untuk mempermudah proses pekerjaan di lapangan. Pemilihan alat berat tersebut tergantung pada karakteristik masing-masing alat dan keadaan di lapangan. Hal ini diperlukan agar alat tersebut dapat bekerja sesuai dengan rencana yang tepat waktu dan pekerjaan yang telah ditetapkan. Adapun pekerjaan tanah meliputi dari pekerjaan galian dan pekerjaan timbunan. Pekerjaan galian tanah dikerjakan dengan bantuan alat berat. Dalam pelaksanaan pekerjaan galian material, digunakan alat berat seperti excavator, dumptruck dan shovel.

Menurut Rostyanti, (2008) Alat berat memiliki banyak jenisnya, sehingga pemilihan alat berat harus disesuaikan dengan kebutuhan di lapangan. Pemilihan alat tepat akan berpengaruh terhadap produktivitas dan tercapainya target pekerjaan.
Produktivitas alat berat adalah kemampuan alat berat dalam menyelesaikan pekerjaan yang dihitung dalam satuan waktu, produktivitas alat berat tergantung pada kapasitas bucket, bucket faktor, cycletime dan faktor koreksi produksi.

Begitu pula pada Proyek Refinery PT. Salim Ivomas Pratama,Tbk berada di Jalan Tanjung Tembaga No. 2-6, Krembangan, Perak Barat, Surabaya dengan luas area $24 \times 6.6 \mathrm{~m}^{2}$ dan kedalaman galian $-4 \mathrm{~m}$. Jenis tanah pada lokasi galian adalah jenis tanah asli. Kendala yang dihadapi pada saat proses penggalian adalah akses jalan yang sempit sehingga mobilisasi alat berat terbatas. Pada proyek digunakan 5 jenis alat berat yaitu 1 shovel, 2 Excavator Komatsu Type PC 200 dan CAT PC 320 serta 2 Dumptruck Type Hino 130 HD dan Mitshubishi Fuso. Dengan kondisi akses jalan yang sempit akan mengakibatkan keterlambatan waktu jika semua alat berat digunakan secara bersamaan. Selain itu apabila alat berat digunakan secara bersamaan produktivitas alat berat kurang efektif. Sehingga dibutuhkan kombinasi walaupun dengan akses jalan yang sempit. Salah satunya dengan melakukan percobaan kombinasi alat berat pada proyek galian refinery PT. Salim Ivomas Pratama, Tbk untuk diperoleh nilai produktivitas yang paling efektif. 
METODOLOGI PENELITIAN

Berikut langkah - langkah untuk memulai penelitian

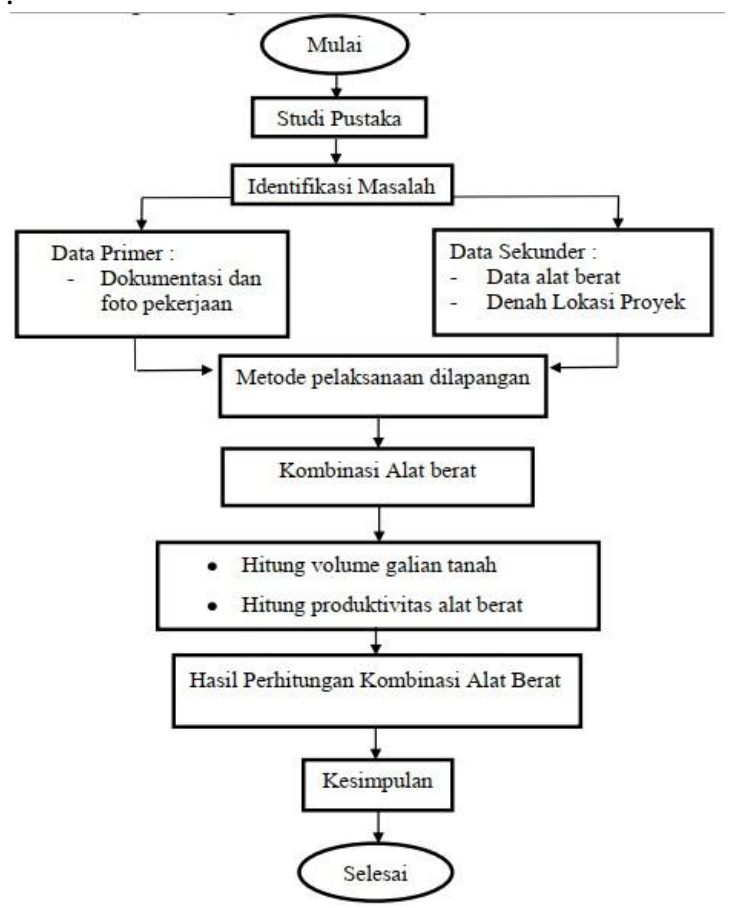

Gambar 1. Bagan Alir Penelitian

\subsection{Pengumpulan Data}

Sumber data yang diperoleh dalam penelitian mengenai produktivitas alat berat pada proyek pembangunan refinery PT. Salim Ivomas Pratama, Tbk antara lain :

1. Data Primer

2. Data Sekunder

\section{ANALISIS DAN PEMBAHASAN}

\section{Data Pekerjaan Proyek}

Pada pelaksanan proyek penggalian di PT. Salim Ivomas Pratama, Tbk yang berlokasi di Perak, Surabaya di peroleh data sebagai berikut :

a. Volume pekerjaan galian tanah

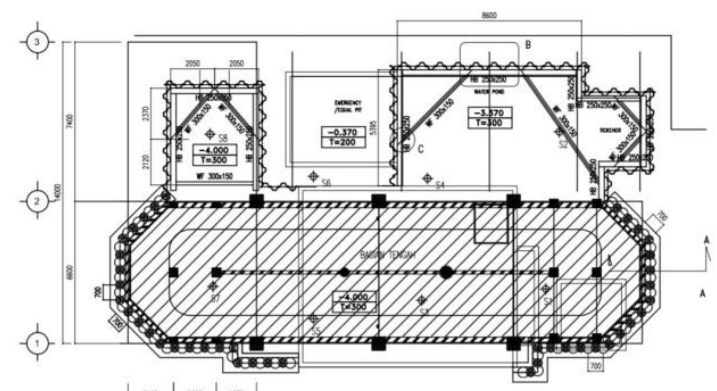

Sumber :PT. Lintech Duta Pratama,

Gambar 2. Area Galian Lahan

Volume 1 p.panjang $=\mathrm{p} \mathrm{x} 1 \mathrm{x} \mathrm{t}$

$=24 \times 6,6 \times 4=633,6 \mathrm{~m}^{3}$

Volume 11 trapesium

$=(1 / 2 \times(\mathrm{a}+\mathrm{b}) \times \mathrm{t}) \times 2$

$=(1 / 2 \times(2,350+6,6) \times 4) \times 2$
$=17,9 \times 2=35,8 \mathrm{~m}^{3}$

Voume total = volume $1+$ volume 11

$=633,6+35,8=669,4 \mathrm{~m}^{3}$

b. Jam kerja $\quad: 8$ jam/hari

c. Jenis tanah : tanah asli

\section{Perhitungan Produktivitas Alat Berat yang direncanakan}

4.3.1 Produksi Shovel

$>$ Produksi Shovel type A

Merk dan Type alat $=$ Komatsu PC 2000

Kapasitas bucket $=0,80 \mathrm{~m}^{3}$

Faktor bucket $(\mathrm{K})=0.8=0,8$

waktu gali $\quad=25$ detik

waktu buang $\quad=20$ detik

waktu swing $\quad=25$ detik

Kedalaman galian $\quad=4 \mathrm{~m}$

Tinggi slump $\quad=1 \mathrm{~m}$

Jam Kerja/Hari $\quad=8$ jam

- Volume tanah asli

- Waktu siklus $(\mathrm{Cm})$

$\mathrm{Cm}=$ waktu gali $+(2 \mathrm{x}$ waktu swing $)+$ waktu buang

$$
=25+(2 \times 20)+25=90 \text { detik }
$$

- Ketinggian optimum $=40 \% \times 4 \mathrm{~m}=1.6 \mathrm{~m}$

- Jenis tanah adalah lempung basah, maka didapat nilai $50-90 \%$, diambil $80 \%$

- Produktivitas untuk setiap jam (60 menit - jam : (90 detik / 60 detik - menit) $) \times 0,80 \mathrm{~m}^{3} \times 1 \mathrm{~m}=$ $32 \mathrm{~m} / \mathrm{jam}$

Produksi Excavator type A

Merk dan Type alat = Komatsu PC 200

$>$ Kapasitas bucket $\left(\mathrm{q}^{1}\right) \quad=0.75 \mathrm{~m}^{3}$

Faktor bucket $(\mathrm{K}) \quad=$ Waktu siklus

$>$ Waktu gali $=25$ detik

$>$ Waktu putar $\quad=20$ detik

Waktu buang = 25 detik

$>$ Waktu siklus $(\mathrm{Cm})$

$\mathrm{Cm}=$ waktu gali + waktu putar $\mathrm{x} 2+$ waktu buang $=25+(20 \times 2)+25$

$=90 \mathrm{detik} / \mathrm{siklus} \approx 1.50 \mathrm{menit} / \mathrm{siklus}$

Produksi per siklus ( q )

$\mathrm{q}=\mathrm{q} 1 x k$

$=0.75 \times 0.80$

$=0.6 \mathrm{~m} / \mathrm{siklus}$

Produksi Excavator per jam $9 \mathrm{~m}^{3} / \mathrm{jam}$ )

$\mathrm{Q}=\frac{q \times 60 \times E}{\mathrm{Cm}}$

$=\frac{0,6 \times 60 \times 0,83}{1,50}$

$=19,9 \mathrm{~m}^{3} / \mathrm{jam}$

Produksi Excavator type B 
Merk dan type alat $=$ Excavator Long arm pc 320

Kapasitas bucket $(\mathrm{q} 1) \quad=0,90 \mathrm{~m}^{3}$

Faktor bucket $(\mathrm{K})=0,80$

Waktu siklus

Waktu gali

$=30$ detik

Waktu isi

$=25$ detik

Waktu buang

$=30$ detik

Produksi per siklus $(\mathrm{q})=\mathrm{q} 1 \mathrm{x} \mathrm{k}$

$$
\begin{aligned}
& =0.90 \times 0.80 \\
& =0.72 \mathrm{~m}^{3} / \text { siklus }
\end{aligned}
$$

Waktu siklus ( $\mathrm{Cm}$ )

= waktu gali + waktu putar x 2 + waktu buang

$=30+(10 \times 2)+12$

$=62 \mathrm{detik} / \mathrm{siklus} \approx 1 \mathrm{menit} / \mathrm{siklus}$

Produksi per jam ( $\left.\mathrm{m}^{3} / \mathrm{jam}\right)$

$$
\begin{aligned}
\mathrm{Q} & =\frac{q \times 60 \times E}{C m} \\
& =\frac{0,72 \times 60 \times 0,76}{1} \\
& =32,8 \mathrm{~m}^{3} / \mathrm{jam}
\end{aligned}
$$

\section{$3 \quad$ Produksi Dumptruck}

\section{Produksi Dump Truck Tipe A}

- Merk dan model alat = Hino Dutro $130 \mathrm{H}$

- Jam kerja per hari = $\quad=8$ jam

- Kapasitas Dump Truck (V) = $10 \mathrm{~m}^{3}$

- Jarak pembuangan $\quad=17,5 \mathrm{~km}$

- Faktor efisiensi alat $(\mathrm{E})=0.75$

- Kapasitas pemuat (Excavator) $\mathrm{q} 1=0.83 \mathrm{~m}^{3}$

- Faktor bucket dari excavator $\mathrm{K}=0,9$

- Kecepatan rata-rata bermuatan (V1) $\mathrm{V} 1: 25 \mathrm{~km} / \mathrm{jam} \approx 334 \mathrm{~m} / \mathrm{menit}$

- Kecepatan rata-rata kosong (V2) $\mathrm{V} 2: 35 \mathrm{~km} / \mathrm{jam} \approx 500 \mathrm{~m} / \mathrm{menit}$

Mencari waktu siklus untuk mengetahui jangka waktu yang diperlukan alat-alat berat untuk menyelesaikan satu lingkaran operasi.

Waktu siklus

$>$ waktu damping (t1) : 0,60 menit

$>$ waktu ambil posisi (t2) : 0,80 menit

$>$ waktu pengisian $(\mathrm{t} 3) \quad: 17$ menit

$>$ waktu tempu isi (t4) : (L: V1) x 60

$:(17,5: 25) \times 60$

: 42 menit

waktu tempu kosong (t5) : (L : V2) x 60

$:(17,5: 35) \times 60$

: 30 menit

Sehingga total waktu siklus $(\mathrm{Cm})$ adalah

$$
\begin{aligned}
\mathrm{Cm} & =\mathrm{t} 1+\mathrm{t} 2+\mathrm{t} 3+\mathrm{t} 4+\mathrm{t} 5 \\
& =0,60+0,80+17+42+30 \\
& =91 \text { menit }
\end{aligned}
$$

Jumlah siklus excavator dalam mengisi Dump Truck adalah

$$
\begin{aligned}
& \mathrm{N}=\frac{\mathrm{q}}{\mathrm{a1} \mathrm{x} \mathrm{K}} \\
& =\frac{10}{0.83 \times 0.9}=13,38 \approx 14 \text { siklus }
\end{aligned}
$$

Produksi per siklus adalah

$$
\mathrm{Q}=\frac{C \times 60 \times E}{C m}
$$

$$
=\frac{10,45 \times 60 \times 0,75}{91}=5,16 \mathrm{~m}^{3} / \mathrm{jam}
$$

Produktivitas Dump Truck per jam $=5,16 \mathrm{~m}^{3} / \mathrm{jam}$

\section{Produksi Dump Truck Tipe B}

- Merk dan model alat = Mitsubishi Fuso

- Jam kerja per hari $\quad=8$ jam

- Kapasitas Dump Truck (V) $=12 \mathrm{~m}^{3}$

- Jarak pembuangan $(\mathrm{L}) \quad=500 \mathrm{~m}$

- Faktor efisiensi alat $(\mathrm{E}) \quad=0.75$

- Kapasitas pemuat (Excavator) $\mathrm{q} 1=0,97 \mathrm{~m}^{3}$

- Faktor bucket dari excavator $\mathrm{K}=0,80$

Kecepatan rata-rata bermuatan (V1) $\mathrm{V} 1: 30 \mathrm{~km} / \mathrm{jam} \approx 500 \mathrm{~m} / \mathrm{menit}$

Kecepatan rata-rata kosong (V2) $\mathrm{V} 2: 45 \mathrm{~km} / \mathrm{jam} \approx 750 \mathrm{~m} / \mathrm{menit}$

Mencari waktu siklus untuk mengetahui jangka waktu yang diperlukan alat-alat berat untuk menyelesaikan satu lingkaran operasi. Waktu siklus waktu damping (t1) $\quad: 0.60$ menit waktu ambil posisi (t2) $\quad: 0.60$ menit waktu pengisian (t3) : 20 menit waktu tempu isi (t4) : (L : V1) x 60

$$
:(17,5: 30) \times 60
$$

$$
\text { : } 35 \text { menit }
$$

waktu tempu kosong (t5) : (L : V2) x 60

$$
\begin{aligned}
& :(17,5: 45) \times 60 \\
& : 24 \text { menit }
\end{aligned}
$$

Sehingga total waktu siklus $(\mathrm{Cm})$ adalah

$$
\begin{aligned}
\mathrm{Cm} & =\mathrm{t} 1+\mathrm{t} 2+\mathrm{t} 3+\mathrm{t} 4+\mathrm{t} 5 \\
& =1+1+20+35+24 \\
& =81 \text { menit }
\end{aligned}
$$

Jumlah siklus excavator dalam mengisi Dump Truck adalah $\mathrm{N}=\underline{\mathrm{q}}$

$$
\begin{aligned}
& \mathrm{q} 1 \times \mathrm{K} \\
&=\frac{10}{0.83 \times 0.9}=13,38 \approx 14 \text { siklus }
\end{aligned}
$$

Produksi per siklus adalah

$$
\begin{aligned}
C & =n \times q 1 \times K \\
& =14 \times 0.83 \times 0.9 \\
& =10,45 \mathrm{~m}^{3}
\end{aligned}
$$

Maka produksi Dumb truck per jam adalah

$$
\begin{aligned}
C= & \frac{C \times 60 \times E}{C m} \\
& =\frac{10,45 \times 60 \times 0,75}{81}=5,80 \mathrm{~m}^{3} / \mathrm{jam}
\end{aligned}
$$


Tabel 1. Pendawalan Kombinasi Excavator A, B dan Dumb Truck A

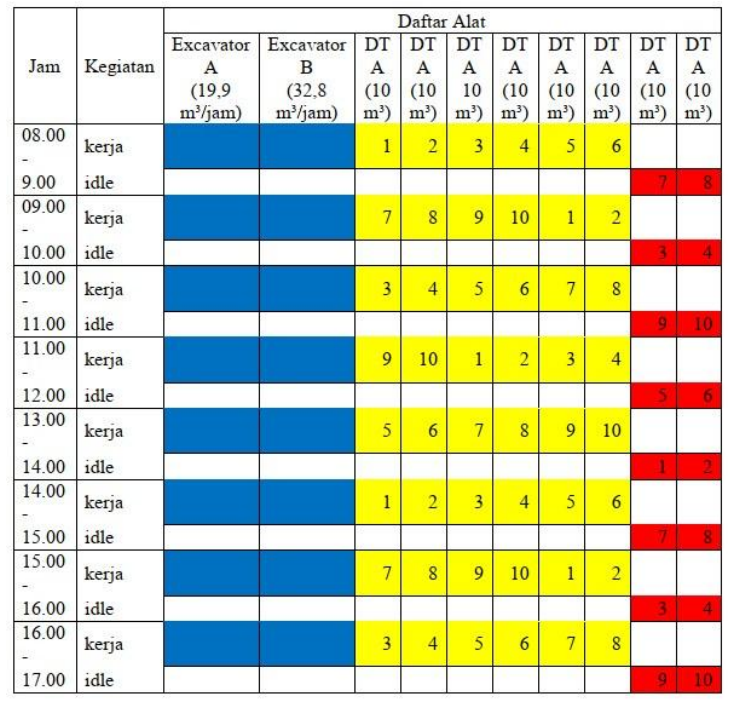

Tabel 2. Penjadwalan kombinasi excavator A, B dan Dumb Truck B

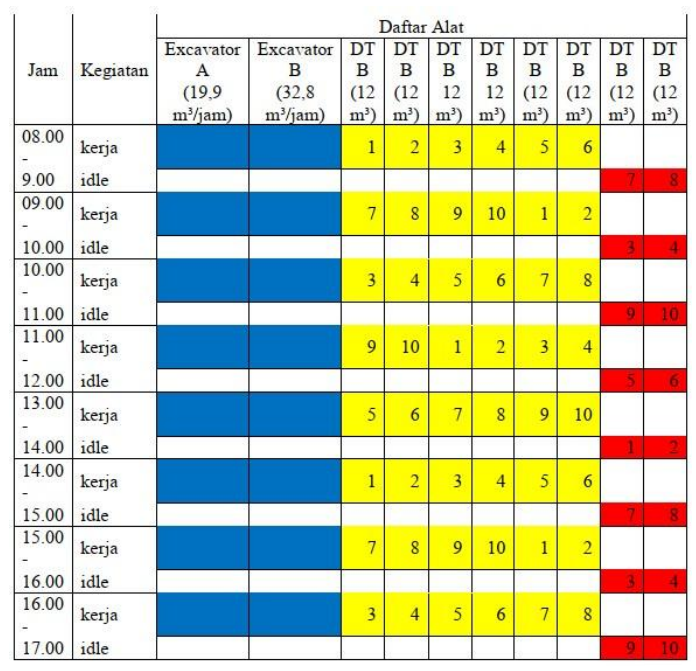

Tabel 3. Penjadwalan kombinasi excavator A, Shovel dan Dumb Truck A

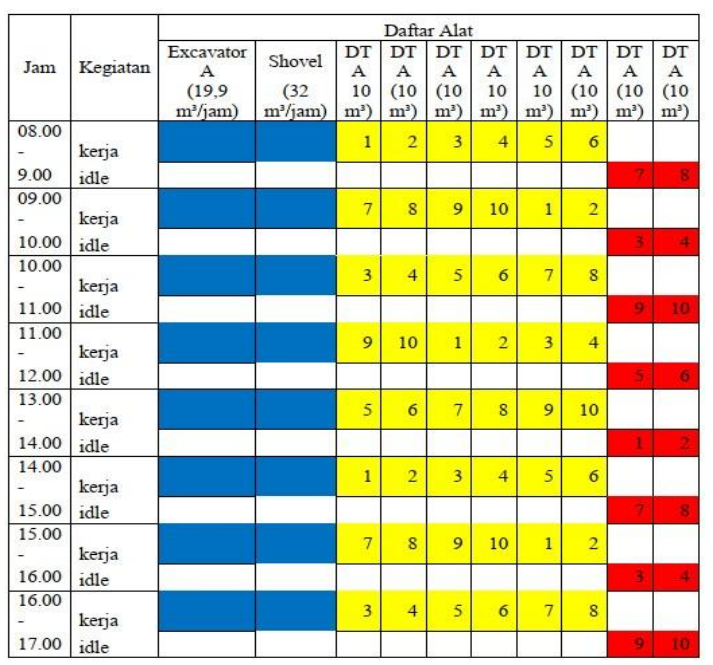

Tabel 4. Penjadwalan kombinasi excavator B, Shovel dan Dumb Truck A

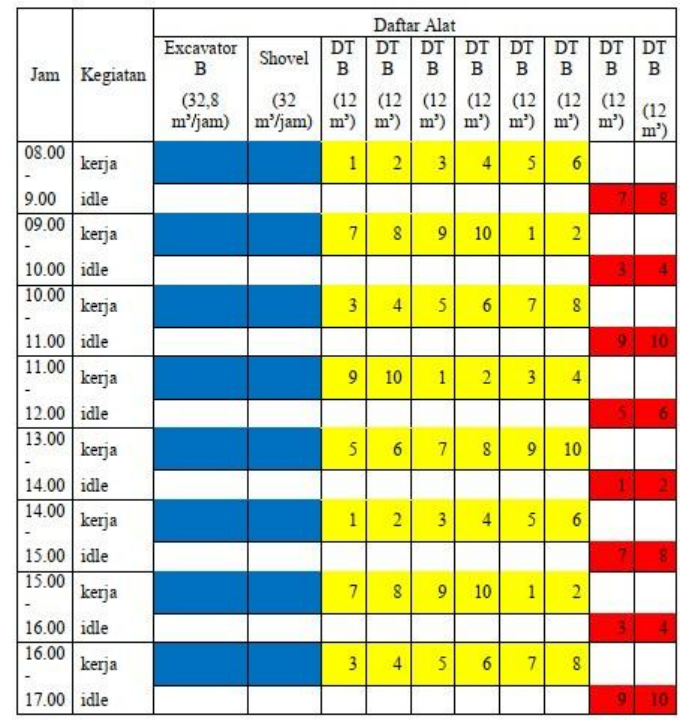

Tabel 5. Penjadwalan kombinasi excavator B, shovel dan dumb truck B

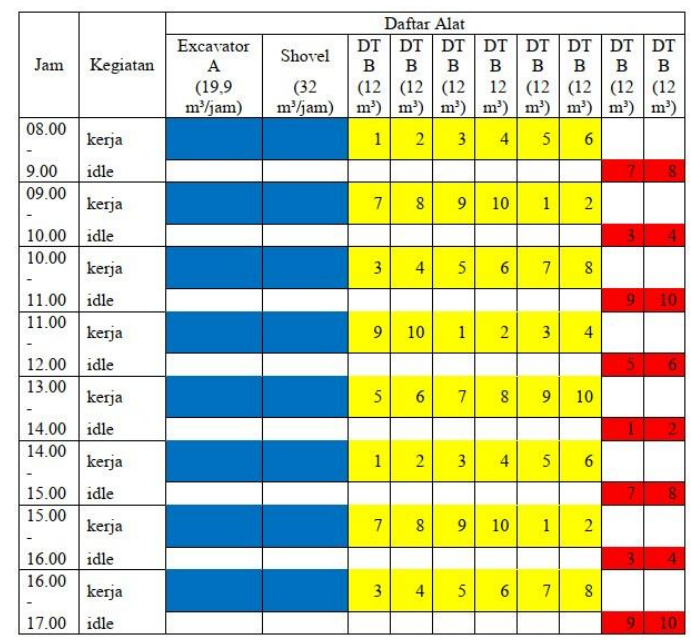

Tabel 6. Penjadwalan kombinasi excavator B dan dumb truck B

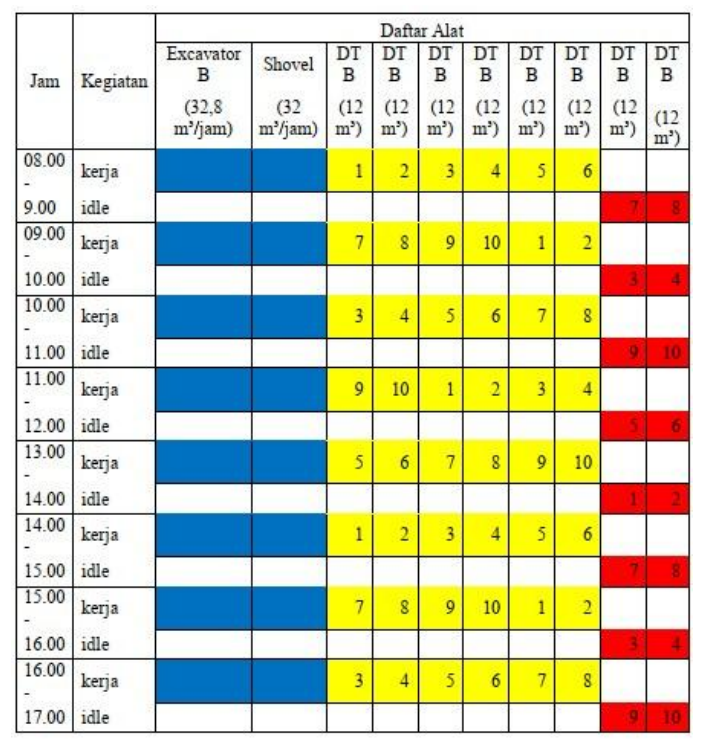




\section{KESIMPULAN}

Hasil perhitungan dari produktivitas alat berat antara produksi per jam dan produksi per hari pada proyek pembangunan refinery PT. Salim Ivomas Pratama, Tbk dapat diambil beberapa kesimpulan sebagai berikut :

1. Hasil produktivitas alat berat pada pekerjaan galian di proyek pembangunan refinery PT. Salim Ivomas Pratama, Tbk total produktivitas untuk excavator komatsu pc $75=40,5 \mathrm{~m}^{3} / \mathrm{jam}$, excavator komatsu pc $200=57,9 \mathrm{~m}^{3} / \mathrm{jam}$, untuk excavator Long Arm = $360,9 \mathrm{~m}^{3} / \mathrm{jam}$, produktivitas dump truck HINO dutro $130 \mathrm{HD}=224,6 \mathrm{~m}^{3} /$ hari, total produktivitas dump truck Mitsubishi FUSO $=381,5 \mathrm{~m}^{3} /$ hari, dan total produktivitas dump truck HINO fm 260 JD $=524,9$ $\mathrm{m}^{3} /$ hari.

2. Kombinasi keempat terdiri dari 1 unit Shovel, 1 unit excavator dengan unit excavator dengan jenis/tipe Long Arm 320 dengan kapasitas bucket $0,90 \mathrm{~m}^{3}$ dan 10 unit dump truck jenis/tipe Hino dutro $130 \mathrm{HD}$ dengan kapasitas $10 \mathrm{~m}^{3}$. Total produktivitas untuk shovel didapat dari $32 \mathrm{~m}^{3}$ produktivitas/jam x 8 jam kerja/hari $=256 \mathrm{~m}^{3} /$ hari, Total produktivitas untuk excavator didapat dari $32,8 \mathrm{~m}^{3}$ produktivitas/jam x 8 jam kerja/hari $=262,4 \mathrm{~m}^{3} /$ hari dan total produktivitas dump truck didapat dari $5,16 \mathrm{~m}^{3}$ produktivitas/jam x 8 jam kerja/hari $=41,3 \mathrm{~m}^{3} /$ hari. Kombinasi keempat menghasilkan waktu 25 hari.

\section{DAFTAR PUSTAKA}

Asianto, 2008. Manajemen Alat Berat Untuk Konstruksi. Jakarta: PT Pradnya Paramita.

Brosur Excavator komatsu. (05 Maret 2018). Spesifikasi Excavator $\quad$ PC 200 (Online),(https://home.komatsu>worldwide.pdf, 2018).

Brosur Excavator CAT. (05 Maret 2018). Spesifikasi Excavator Long Arm PC 320. (Online), (https://ekatalog.scene7.com>produk>.pdf, 2018).

Brosur Dumptruck HINO. (05 Maret 2018). Spesifikasi HINO Dutro 130HD. (Online), (https://ekatalog.lkpp.go.id>produk> hino.pdf, 2018).

Brosur Dumptruck HINO. (05 Maret 2018). Spesifikasi Mitshubishi FUSO. (Online), (https://ktbfuso.co.id>donwloadbrochure.pdf, 2018).

Gafur, 2012. AnalisaPerhitungan Produktivitas Alat

Berat Pada Pelaksanaan Pematangan Lahan Untuk Pembuatan Work Shop Di Kab. Malinau Pada Dinas Pekerjaan Umum Provinsi
Kalimantan Timur Universitas 17 Agustus Samarinda Provinsi Kalimantan Timur. KURVA S Volume 1 Nomer 1 (2012) Universitas Sultan Ageng

Tirtayasa. Jurnal Sipil Statik, (Online), (http://ejurnal.untag.snd.ac.id/index.php/TEK/artic le/view/124,diakses 21 Maret 2018.

Nunnally, S. W. 2007. Construction Methods and Management, Seventh Edition. Prentice Hall, Inc. Jurnal Sipil Statik, (Online), (www.icivil-hu.com $>\quad$ civil-team>92578022-Construction-Methodsand-Management.pdf, diakses 05 April 2018)

Rochmanhadi, 1992. Alat berat dan Pengunaannya. Jakarta: Departemen Pekerjaan Umum.

Rostiyanti, Susy Fatena, 2008. Alat Berat Untuk Proyek Konstruksi, Jakarta: Penerbit Rineka Cipta, Hlm. 6.

Setiawati dkk., 2013. Analis Produktivitas Alat Berat Pada Proyek Pembangunan Pabrik Krakatau Posco Zone IV Di Cilegon Jurnal Konstruksia, Volume 4 Nomer 2 Juni 2013. Jurnal Sipil Statik, (Online), (download.portalgaruda.org > article > titleipi321516.pdf ,diakses 21 Maret 2018). Soeharto, Imam, 1997. Manajemen Proyek. Edisi kedua. Konsep, study kelayakan dan jaringan kerja Jakarta: Erlangga

Susanto dkk., 2015. Produktivitas Alat Berat Pada Pekerjaan Galian Gedung P1 P2 Uk Petra. Universitas Kristen Petra. Jurnal Sipil Statik, (Online), (publication.petra.ac.id > article > view, diakses 21 Maret 2018). 
Halaman Sengaja Dikosongkan 